\title{
Protease Inhibitor (Pi) Phenotyping in Light Breed Horses on Isoelectric Focusing Using Urea-Polyacrylamide Gel
}

\author{
Hironaga KAKOI, Michiru YAMAKAWA \\ and Hitoshi GAWAHARA \\ Laboratory of Racing Chemistry, Setagaya-ku, Tokyo 158
}

(Received May 24, 1995)

\begin{abstract}
Isoelectric focusing (IEF) using polyacrylamide gel containing urea (Urea-PAG) was used for the characterization of equine protease inhibitor ( $\mathrm{Pi}$ ) types in light breed horses to solve the following problems in conventional IEF and two-dimensional (2-D) electrophoresis : typing complexity due to high heterogeneity of $P i$ system and overlapping of $\mathrm{Pi}$ and esterase (Es) components on IEF, operational complexity and time-consumption on 2-D. The Urea-PAG IEF method had high resolution capacity, clearly distinguishing at least 10 types frequently observed in light breed horses. Es components were not detected on Urea-PAG. There was little complexity of Pi typing as shown by these results, and thus the typing procedure is simpler and more rapid than conventional IEF and 2-D. The present method should thus prove quite adequate for exact classification of $P i$ system in light breed horses.
\end{abstract}

Anim. Sci. Technol. (Jpn.) 66 (10) : 849-853, 1995

Key words : protease inhibitor type, IEF, light breed horse,

The equine protease inhibitor $(P i)$ system is the most polymorphic genetic among horse blood typing systems, and at least 18 alleles have been assigned by this system following the International Society for Animal Genetics (ISAG) Workshop discussion for the 1993 Horse Comparison Test (HCT). The Pi system is considered a very useful blood typing marker for identification and parentage testing owing to its highly polymorphic nature. Some informative typing techniques have thus been established and used for the classification of $P i$ alleles $^{1,3-6)}$.

The horizontal isoelectric focusing (IEF) method reported by Yokohama and $\mathrm{Mogi}^{12)}$ is a very useful typing technique for the $P i$ system and is routinely used as a conventional method in horse blood typing. However, this method has complexity on Pi system because Pi protein has high heterogeneity and is detected at the same isoelectric point (pI) region where the $F$ band of esterase (Es) system is located. Yokohama et al..$^{13,14)}$ adopted the microscale multisample two dimensional electrophoresis (2-D) method to solve these problems. This 2D technique separated Pi components from Es components and characterized the respective $\mathrm{Pi}$ types in light breed horses. It is thus

㽷菜加ポリアクリルアミドゲル等電点電気泳動法による軽種馬のPiフェノタイピング：栫 裕永・山川ミチル・ 側原 二(競走馬理化学研究可, 東京都世田谷区 158) 


\section{KAKOI, YAMAKAWA and GAWAHARA}

routinely used as a confirmative step for typing when classification of $\mathrm{Pi}$ types on the IEF testing is complicated. However, there is an operational difficulty in this method in contrast to horizontal IEF, causing it to be timeconsuming. To solve this problem and establish a simpler and more rapid routine typing, the horizontal IEF method should have high resolution capacity and the capacity to separate $\mathrm{Pi}$ and Es components. Therefore, in the present study, polyacrylamide gel containing urea was used for electrofocusing as a novel technique, and the capacity to separate Pi and Es components by denaturation of urea was examined. Potentiality for the resolution and repeatability was also assessed.

Specifically, the exact classification of $P i$ alleles in light breed horses has an important purpose for blood typing service as a part of their pedigree registration. The following $P i$ alleles, $P i^{F}, P i^{G}, P i^{I}, P i^{L}, P i^{M}, P i^{N}, P i^{s}, P i^{S t}, P i^{U}$ and $P i^{L I}\left(P i^{S I}\right.$ and $P i^{L I}$ alleles have been identified and assigned to ISAG nomenclatural $P i^{T}$ and $P i^{L 2}$ alleles, respectively), were frequently observed in light breed horses as reported previously ${ }^{12)}$. Therefore, the usefulness of the present technique for routine typing of these 10 types in light breed horses is discussed.

\section{Materials and Methods}

\section{Samples:}

Serum samples were obtained from 950 horses consisting of 601 Thoroughbreds and 349 Anglo-Arabs whose Pi phenotypes had been determined by conventional IEF or 2-D and classified into 55 phenotypes formed from 10 types, namely $F, G, I, L, M, N, S, T, U$ and $L_{2}$. Reducing treatment for samples was performed with $0.25 \mathrm{M}$ dithiothreitol and $10 \mathrm{mM}$ iodoacetoamide at a $2: 1: 2$ ratio for 1 hour at $37^{\circ} \mathrm{C}$ or overnight at $4^{\circ} \mathrm{C}$ as described by Yokohama and Mogi $^{12)}$ with slight modification.

\section{Electrofocusing :}

Electrofocusing was carried out using a thin layer urea-polyaclylamide gel (Urea-PAG). Because the composition of the gel for hemoglobin typing reported by Yokohama and $M o g 1^{10)}$ is simpler than that of the conventional gel for Pi typing, Urea-PAG was prepared in this study using the gel for hemoglobin typing with the following modifications: $0.75 \mathrm{ml}$ SERVALYT (SERVA) AG 4-5 was used as the carrier ampholyte, $7.5 \mathrm{ml} 8 \mathrm{M}$ urea was used instead of distilled water and $30 \mu l$ TEMED were added to the stock solution per gel plate (140 $\mathrm{mm} \times 120 \mathrm{~mm} \times 1 \mathrm{~mm}$ ). $1 \mathrm{M} \mathrm{H}_{3} \mathrm{PO}_{4}$ and $1 \mathrm{~N}$ $\mathrm{NaOH}$ were used as anodal and cathodal buffers, respectively. The gel was electrophoresed initially at $350 \mathrm{~V}(3 \mathrm{~W})$ and last at 1200 $\mathrm{V}$ for 3 hours.

\section{Detection and identification:}

The detection of serum proteins separated by Urea-PAG was carried out by the CBB-R250 staining method as reported previously ${ }^{11)}$. Identification of $\mathrm{Pi}$ components on Urea-PAG was done based on a comparison with known Pi types determined by conventional IEF or 2$D$ testing. The inhibition of bovine trypsin and chymotrypsin for the identification of $\mathrm{Pi}$ components was done as described by Pollitt and Bell ${ }^{8)}$. The procedure for detecting Es activity was the same as that of Gahne ${ }^{2)}$. A1B glycoprotein (A1B) components, i.e., Post albu$\min (\mathrm{Pa})$ or $\mathrm{Xk}$ components, were identified by comparing the present variants with A1B types obtained by conventional IEF which could simultaneously detect variants as reported ${ }^{12)}$.

Calibration of $p I$ on Urea-PAG :

After electrofocusing, 24 aliquot gel fragments obtained from Urea-PAG were dissolved in $5 \mathrm{~m} l$ distilled water. pI on Urea-PAG was determined based on calculated $\mathrm{pH}$ of the solutions.

\section{Results}

Fig. 1 shows electrophoretic patterns on Urea-PAG of serum proteins including $10 \mathrm{Pi}$ types determined by the conventional tech- 


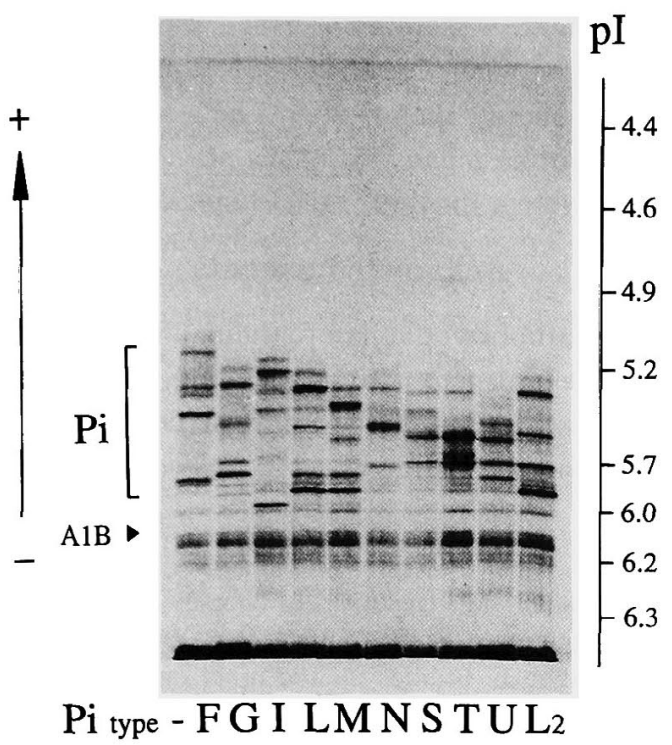

Fig. 1. The respective electrophoretic patterns of 10 basic Pi types (F, G, I, L, M, N, S, T, U and $\mathrm{L}_{2}$ ) in light breed horses using Urea-PAG.

nique. These visible patterns were separated into two regions, one consisting of multiple bands and the other, minor bands, the same as by conventional method. No inhibition of trypsin and chymotrypsin for these detected bands was observed, and consequently the Pi components could not be identified by this method. However, typing results of the multiple bands on Urea-PAG were completely consistent with those of the $P i$ system as determined by conventional IEF and 2-D testing, using 950 samples. These bands were thus considered $\mathrm{Pi}$ components ( $\mathrm{Pi}$ in Fig. 1). The electrophoretic behavior of the minor bands was identical to that of $\mathrm{A} 1 \mathrm{~B}$ components in conventional IEF.

The bands indicating $\mathrm{Pi}$ components on Urea-PAG were sharply separated and respective Pi types were quite distinguishable. All heterozygous types formed from 10 types could be distinctly seen. The resolution results of the bands showed high repeatability.

No Es components were detected within the region of Pi components by the present method
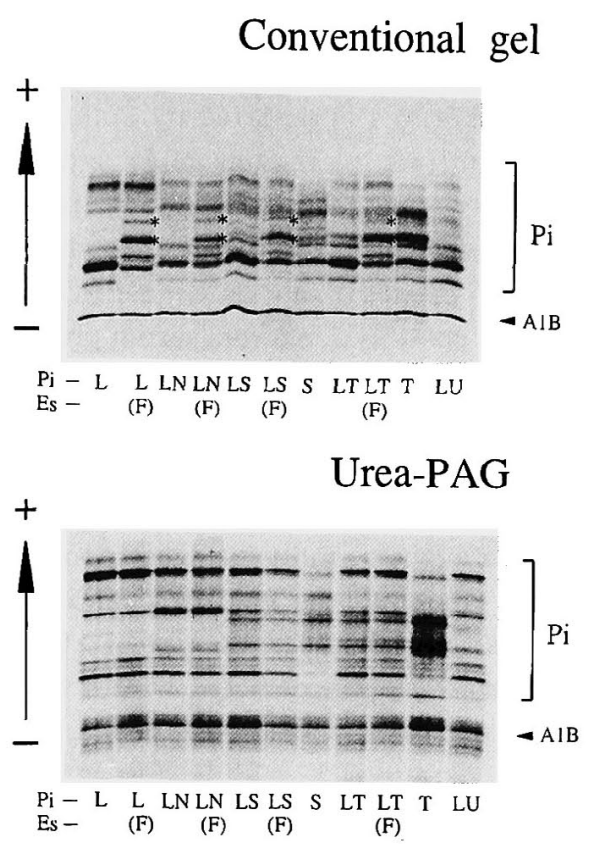

Fig. 2. A comparison of electrophoretic behaviors of $\mathrm{Pi}$ and Es components on conventional IEF and Urea-PAG IEF. The respective phenotypes in $P i$ and $E s$ system are shown ; $(F)$ in $E s$ system indicates the phenotype including $F$ type, and the asterisked bands on the conventional gel indicate the $\mathrm{F}$ bands in Es system.

(Fig. 2). This component could not be visualized by $\mathrm{CBB}$ staining nor could its activity be confirmed at all using Urea-PAG.

Although the regional patterns of $\mathrm{Pi}$ and $\mathrm{A} 1 \mathrm{~B}$ components on Urea - PAG apparently resembled those of the conventional gel as mentioned above, each estimated $\mathrm{pI}$ region of $\mathrm{Pi}$ and $\mathrm{A} 1 \mathrm{~B}$ components was higher than those determined using the conventional gel. The former was from 5.1 (at the upper band of $F$ type) to 6.0 (at the bottom band of I type) and the latter, 6.1 (Fig. 1).

\section{Discussion}

By the present method, the serum proteins, $\mathrm{Pi}$ and $\mathrm{A} 1 \mathrm{~B}$ components, were detected in a higher $\mathrm{pI}$ region even though Yokohama et al. . $^{\text {) }}$ reported they could be observed within the pI 
region from 3.5 to 5.2. Estimated pI of Pi components on Urea-PAG clearly differed from those from 3.74 to 4.43 reported by Pollitt and $B e 11^{7}$. In contrast, $\mathrm{pl}$ regions of $\mathrm{Pi}$ and $\mathrm{A} 1 \mathrm{~B}$ components were identical to previous results when a gel with the same composition as that of Urea-PAG except urea (non Urea-PAG) was used. Thus possibly separated serum proteins using Urea-PAG are at least denatured by urea. It then follows that negative response to the inhibition of trypsin and chymotrypsin is due to denaturation of Pi components. Denaturation by urea may also influence Es components since they could not be visualized and their activity was not observed on Urea-PAG. In fact, they were clearly detected within the $\mathrm{Pi}$ region and activity was observed on non UreaPAG.

Although detected proteins using Urea-PAG should be regarded as denatured, as for the phenotyping of $P i$ system, the present method is recognized as having high capacity to distinguish at least 55 phenotypes consisting of $10 \mathrm{Pi}$ types in light breed horses because of the high resolution capacity. In the conventional method, $\mathrm{S}$ and $\mathrm{T}$ types were particularly difficult to distinguish when they formed heterozygotes with other $\mathrm{Pi}$ types because $\mathrm{pI}$ of the bands on respective types were very close to those of certain bands found in other $\mathrm{Pi}$ types ${ }^{13.14)}$. Additional difficulty in typing was observed when Es components were detected within the detected region of $\mathrm{Pi}$ components since $\mathrm{pI}$ of bands on $\mathrm{S}$ and $\mathrm{T}$ types were similar to that of the $\mathrm{F}$ band in the Es system (see Fig. 2). However, on Urea-PAG, both $S$ and $T$ types could be clearly distinguished and Es components fortunately were not visualized by denaturation using urea. Thus the above cited difficulty in typing is no longer present even if $S$ and $T$ types are heterozygous with any other type. Therefore, by the Urea-PAG IEF method, it should be possible to classify $\mathrm{Pi}$ phenotypes distinctly in spite of high heterogeneity. Also it is suggested that 2-D testing as a confirmative step is not necessary in Pi routine typing when Urea-PAG IEF is used. This method should thus prove to be a simple and rapid routine means for exact phenotyping in the $P i$ system for light breed horses.

\section{Acknowledgements}

The authors would like to thank all members of the Department of Blood Typing, Laboratory of Racing Chemistry for their cooperation and encouragement.

\section{References}

1) Braend M. Genetics of horse acidic prealbumins. Genetics, 68 : 495-503. 1970.

2) Gahne B. Studies on the inheritance of electrophoretic forms of transferrins, albumins, prealbumins and plasma esterases of horses. Genetics, 53 : 681-694. 1966.

3) Henney PJ, Johnson EL, Cothran EG. A new buffer system for acid PAGE typing of equine protease inhibitor. Anim. Genet., $25: 363-364$. 1994.

4) Juneja RK, Gahne B, Sandberg K. Genetic polymorphism and close linkage of two protease inhibitors in horse serum. Anim. Blood Grps Biochem. Genet., $10: 235-251.1979$.

5) Matthews AG. Isoelectric focusing of horse acidic prealbumins in thin layer polyacrylamide gels. Anim. Blood Grps Biochem. Genet., $10: 219-226.1979$.

6) Pollitl CC, Bell K. Protease inhibitor system in horses : classification and detection of a new allele. Anim. Blood Grps Biochem. Genet, 11 : 235-244. 1980.

7) Pollitt CC, Bell K. Characterisation of the $\alpha 1$ protease inhibitor system in Thoroughbred horse plasma by horizontal two-dimensional (ISO-DALT) electrophoresis. 1. Protein staining. Anim. Blood Grps Biochem. Genet., $14: 83^{-}$ 105. 1983.

8) Pollitt CC, Bell K. Characterisation of the $\alpha 1$ protease inhibitor system in Thoroughbred horse plasma by horizontal two-dimensional (ISO-DAL.T) electrophoresis. 2. Protease in hibition. Anim. Blood Grps Biochem. Genet., 14 : 107-118. 1983.

9) Yokohama M, Mogi K, Suzuki S. Xk type of equine serum detected by iso-electrofocusing techniques. ABRI, $11: 43-46.1983$. 
10) Yokohama $M$, Mogi $K$. Polymorphism of equine hemoglobin by the isoelectric focusing method. Jpn. J. Zootech. Sci., 54 : 794-797. 1983.

11) Yokohama $M$, Watanabe $Y$, Mogi K. A new equine transferrin phenotype detected by isoelectric focusing. Jpn. J. Zootech. Sci., 56 : 116121. 1985.

12) Yokohama M, Mogi K. Detection of the protease inhibitor $(\mathrm{Pi})$ systems of the light breed horses by isoelectric focusing. Jpn. J. Zootech.
Sci., $56: 883-888.1985$.

13) Yokohama M, Gawahara $H$, Mogi $K$. On the characterization of the $\alpha 1$-protease inhibitor (Pi) types in light breed horses using microscale multisample two-dimensional electrophoresis. Jpn. J. Zootech. Sci., 58 : 253-258. 1987.

14) Yokohama $M$, Watanabe $Y$. On the classification of protease inhibitor ty pes in light-breed horses. Phisico-Chem. Biol., 32 ; 121-124. 1988. 